\title{
A participação da criança no currículo e na avaliação: reflexões a partir do registro escrito
}

\section{The participation of children in the curriculum and in the assessment: reflections from the written record}

\author{
Cristina Aparecida Colasanto, graduada em Pedagogia, possui \\ Mestrado em Linguística Aplicada e Estudos da Linguagem e \\ Doutorado em Educação: Currículo pela Pontifícia Universidade \\ Católica de São Paulo (PUC-SP). Atualmente é professora de \\ Ensino Superior da Anhanguera Educacional e Coordenadora \\ Pedagógica da Prefeitura do Município de São Paulo.
}

Contato: criscolasanto@yahoo.com.br

\section{Resumo}

0 objetivo deste artigo é apresentar o resultado de alguns registros de relatórios de avaliação, elaborados por professoras de Educação Infantil, em que se evidencie a criança no centro de sua escrita, explicitando assim suas interações e experiências vivenciadas na escola. A pesquisa foi desenvolvida seguindo a metodologia de pesquisaação, e os resultados revelam que na escrita do relatório a criança torna-se o sujeito principal, resgatando assim suas falas, ações, interações e o acompanhamento do processo de ensino-aprendizagem, desvelando também a proposta curricular da escola. Em avaliação, as entrevistas com as criança indicam o que elas pensam sobre os projetos e atividades desenvolvidas por elas na escola, proporcionando assim o autoconhecimento.

Palavras-chaves: Currículo. Avaliação. Educação Infantil.

\section{Abstract}

The purpose of this paper is to present the results of some assessment reports prepared by teachers of Early Childhood 
Education, in which the child is evidenced in the core of his writing, thus evidencing his interactions and experiences tested in the school. The research was developed following the action research methodology. The results show that, when writing the report, the child becomes the main subject, thus recovering his speeches, actions, interactions and the accompaniment of the teaching-learning process. It also reveals the curricular program of the school. In the assessment, the interviews with children show what they think about projects and activities developed by them in the school, thus providing self-knowledge.

Keywords: Curriculum. Assessment. Early Childhood.

\section{Introdução}

Este artigo é um recorte de uma pesquisa de doutorado realizada no Programa de Pós-Graduação Educação: Currículo da PUC-SP (COLASANTO, 2014) sobre a elaboração de relatórios de avaliação em duas Escolas Municipais de São Paulo (EMEls), cujo foco foi investigar o registro da participação das crianças nesses documentos. 0 objetivo deste trabalho é apresentar os resultados de alguns registros de relatórios de avaliação, elaborados pelas professoras de Educação Infantil, que apresentem a criança no centro de sua escrita, explicitando assim suas interações e experiências vivenciadas durante o período compreendido pela Educação Infantil. Diante do exposto, retratamos neste artigo os dados compilados em uma das escolas participantes da pesquisa.

No Brasil, a avaliação em Educação Infantil segue os princípios propostos pela Lei de Diretrizes e Bases da Educação Nacional (BRASIL, 1996), revisada e alterada pela Lei 12.796 (BRASIL, 2013), cujo item I do artigo 31 define que, na Educação Infantil, a avaliação deve ocorrer "mediante acompanhamento e registro do desenvolvimento das crianças, sem o objetivo de promoção, mesmo para o acesso ao ensino fundamental".

A LDBEN (BRASIL, 1996) propõe que os professores utilizem registros para compor a avaliação das crianças. Assim, a construção dos relatórios de avaliação é uma prática comum realizada em escolas, principalmente na rede municipal de Educação Infantil da cidade de São Paulo. Cada instituição determina a periodicidade de entrega desses relatórios avaliativos aos pais das crianças, ao final de cada bimestre ou no término 
de cada semestre, por exemplo. Cada escola também define os instrumentos de avaliação, seus critérios e procedimentos: registros, fotos, desenhos etc., levando em consideração que a avaliação não pode se apresentar em produto final, como as fichas avaliativas ou outros instrumentos que avaliem a criança em um único momento ou somente ao final de certo período.

0 item $V$ do referido artigo 31, contido na LDBEN/96, revisado pela Lei 12.796, acrescenta a seguinte determinação às escolas: "expedição de documentação que permita atestar os processos de desenvolvimento e aprendizagem da criança". A prática da observação e as variadas formas de registros são, portanto, elementos primordiais para a elaboração da avaliação na Educação Infantil; no decorrer do tempo de permanência da criança na instituição, constrói-se uma documentação que irá revelar o seu desenvolvimento, desde a sua entrada, de forma processual, até a sua saída para outra escola ou para o Ensino Fundamental.

O documento Diretrizes Curriculares Nacionais para a Educação Infantil (BRASIL, 2009a) também orienta as instituições que atendem a essa faixa etária do alunado a criar procedimentos para acompanhar o trabalho pedagógico e para avaliar o desenvolvimento das crianças, sem se esquecer de utilizar a observação crítica e criativa de suas atividades, brincadeiras e interações no cotidiano.

É nessa perspectiva conceitual e no contexto do debate atual sobre a avaliação na e da Educação Infantil (DIDONET, 2012) que me situo enquanto professora de Educação Infantil há 16 anos, e na rede municipal de educação paulistana há 13 anos, na qual ocupo, há cerca de quatro anos, o cargo de coordenadora pedagógica. Além dessas posições, há nove anos atuo como professora do curso de graduação em pedagogia em uma universidade particular, localizada em São Paulo. A questão da avaliação sempre provocou muitas inquietações na minha prática educacional: como realizar a avaliação contínua do desenvolvimento das crianças? Como organizar o registro escrito em relatórios e portfólios'? Como incluir a participação das crianças no instrumento de avaliação?

Esta pesquisa busca, pois, trazer contribuições para a elaboração escrita de relatórios, portfólios e outros instrumentos de avaliação que recorrem ao registro escrito, trazendo a participação das crianças nas atividades cotidianas para a produção escrita do professor. Este trabalho procura contribuir também para a reflexão do professor sobre a própria prática e o processo de ensino-aprendizagem na Educação Infantil.
1. Na Educação Infantil, o portfólio, organizado pelo professor, costuma reunir o trabalho das crianças durante a realização de algum projeto realizado pela turma, ou é montado pela criança individualmente. Geralmente, ele é confeccionado no formato de caixas, pastas e CD-ROM (denominado também portfólio digital). 


\section{Discussão teórica}

\subsection{A participação como proposta curricular}

Arroyo (2011) considera que o currículo, núcleo central e mais estruturado da escola, é um território em disputa. Por isso, ele é cercado por normativas, diretrizes, carga horária, estrutura, configurando uma política e suas relações de poder.

Outro indicador da importância atual do currículo, segundo Arroyo (2011), está na ênfase sobre a avaliação. Estamos vivenciando políticas oficiais nacionais e internacionais que avaliam o currículo que é tratado na sala de aula, em cada turma, em cada escola e em cada estado.

0 currículo é uma área em destaque em razão do uso intensivo e um território em disputa pelo aumento de índices e resultados de avaliação; nessa direção, Freitas (2014) analisa a avaliação externa como uma das formas de padronização, controle do currículo e da cultura escolar, definindo inclusive o dia a dia da escola, sob a vertente de interesses empresariais e do mercado financeiro.

Torna-se necessário considerar a especificidade da Educação Infantil nesse contexto, pois ela também é um território em disputa, por isso precisamos consolidar sua proposta curricular e seus próprios instrumentos de avaliação: relatórios, portfólios, documentação pedagógica. Para isso, os documentos de âmbito nacional oferecem orientações e alternativas relevantes para se pensar em uma escola que tenha a sua própria proposta curricular e considere aspectos culturais e regionais, documentos esses fruto do intenso debate nacional sobre essas questões durante as últimas décadas.

Sabe-se que os documentos sozinhos não garantem um atendimento que respeite os direitos das crianças, como também não garantem a construção de um currículo que corresponda à consolidação desses direitos e uma aprendizagem significativa para elas, mas assumem um passo importante e ainda recente para construção da Educação Infantil brasileira.

Após a homologação da LDBEN (BRASIL, 1996), o primeiro documento de âmbito nacional que discutiu o currículo na Educação Infantil foi o Referencial Curricular Nacional para a Educação Infantil - RCNEI (BRASIL, 1998a). 0 referencial foi elaborado por diversos educadores e estudiosos da área, sob a coordenação da Secretaria de Educação Fundamental (SEF) do 
Ministério da Educação (MEC). Em sua bibliografia encontramse referências a documentos oficiais brasileiros, propostas curriculares estaduais, propostas curriculares municipais, propostas curriculares internacionais e obras de diversos autores nacionais e estrangeiros. Seus três volumes (I - Introdução; II Formação Pessoal e Social; e III - Conhecimento de Mundo) foram publicados em 1998 e se apresentam como guia de orientação, além de servirem como base para discussões entre os profissionais de ensino e para a elaboração de projetos educativos.

Mesmo pautados na LDBEN 9394/96, os RCNEIs (BRASIL, 1998a) não se tornaram obrigatórios nas escolas, por causa da autonomia dos entes federados; nem se dispõem a discutir questões como teorias de aprendizagem, formação de professores, abuso sexual, violência nas escolas. Sua contribuição aos profissionais de Educação Infantil se apresenta da seguinte forma:

\footnotetext{
Se por um lado, o Referencial pode funcionar como elemento orientador de ações na busca de melhoria de qualidade da educação infantil brasileira, por outro, não tem a intenção de resolver os complexos problemas dessa etapa educacional. A busca da qualidade do atendimento envolve questões amplas ligadas às políticas públicas (...) (BRASIL, 1998a, vol. I, p. 14).
}

0 documento apresenta-se, portanto, como um guia de orientação para os sistemas de ensino ou para as escolas na elaboração de seus projetos educativos. Foi distribuído em todo o território nacional e as escolas utilizam-no de diversas formas e com variadas interpretações, desde a visão de um modelo ideal a ser seguido até um documento burocrático a ser reproduzido apenas nos Projetos Pedagógicos, sem relação com a prática.

Cerisara (2002) aponta algumas críticas em relação aos RCNEls (BRASIL, 1998a), dentre elas: a forma prematura de sua elaboração, uma vez que persistia a necessidade de amadurecimento da área antes de discutir um "referencial curricular"; e o fato de terem sido elaborados antes da formação das Diretrizes Curriculares Nacionais de 1999, pelo Conselho Nacional de Educação.

0 processo de elaboração das diretrizes ocorreu nas diferentes modalidades de ensino, tendo seu início no governo de Fernando Henrique Cardoso, e tornaram públicas orientações expressas de como deveria ser pensada e conduzida a educação pública no país. Em 1999 foi publicada a primeira versão das Diretrizes Curriculares Nacionais para Educação Infantil (DCNEI),

As DCNEl foram revisadas em 2009 a partir de ampla discussão 
dos educadores, movimentos sociais, pesquisadores e professores universitários, que expressaram suas preocupações e anseios em relação à Educação Infantil (OLIVEIRA, 2010); entretanto, muitos problemas não foram equacionados: discrepância entre a demanda e oferta de vagas, qualidade, formação docente, infraestrutura etc.

As Diretrizes Curriculares Nacionais para a Educação Infantil, de caráter mandatório, orientam a formulação de políticas, incluindo a de formação de professores e demais profissionais da Educação, e também o planejamento, desenvolvimento e avaliação pelas unidades de seu Projeto Político-Pedagógico, e servem para informar as famílias das crianças matriculadas na Educação Infantil sobre as perspectivas de trabalho pedagógico que podem ocorrer (BRASIL, 2009).

A versão final do documento traz, ainda, a seguinte definição de currículo para a Educação Infantil:

\footnotetext{
O currículo da Educação Infantil é concebido como um conjunto de práticas que buscam articular as experiências e os saberes das crianças com os conhecimentos que fazem parte do patrimônio cultural, artístico, científico e tecnológico. Tais práticas são efetivadas por meio de relações sociais que as crianças desde bem pequenas estabelecem com os professores e as outras crianças, e afetam a construção de suas identidades (BRASIL, 2009a, p. 06).
}

Com tal orientação, o currículo deve articular os saberes do patrimônio cultural e científico aos saberes das crianças, dentro de uma matriz histórica e cultural. Essa proposta rompe a visão técnico-linear de currículo que pressupõe um conjunto de disciplinas com conteúdos aprisionados em uma grade curricular sem considerar a cultura e o contexto social (ABRAMOWICZ, 2006).

Barbosa (2009), em relatório de pesquisa encomendado pelo MEC voltado ao mapeamento e análise das propostas pedagógicas de instituições municipais de Educação Infantil brasileira, verifica a existência de propostas curriculares pautadas na programação de atividades, nas listas de conteúdos a serem transmitidos para as crianças de forma técnica e fragmentada, de acordo com as idades. Alguns currículos analisados utilizam como referência o modelo das disciplinas do Ensino Fundamental e propostas curriculares que têm como eixo as datas comemorativas.

Por outro lado, as DCNEI (BRASIL, 2009a), ao enfatizarem o conjunto de práticas ocorridas na escola que possam se articular com as experiências das crianças, trazem a ideia de que a 
criança está no centro da proposta, assim como a sua interação com outros colegas e educadores. A pesquisa realizada por Barbosa (2009) aponta a distância que há entre as diretrizes e o trabalho realizado pelas escolas, já que o debate conduzido pelos educadores, pesquisadores e movimento social durante o processo de elaboração do documento ainda não atingiu a proposta curricular de alguns municípios.

De acordo com Gimeno Sacristán (2000), a ênfase na criança e no processo educativo é o princípio que apoia a concepção de currículo atrelado à experiência dos alunos nas instituições escolares. Esse foco na experiência dos alunos pode provocar algumas consequências importantes:

a) Se o currículo é fonte da experiência, torna-se necessário analisar as condições ambientais que afetam tal experiência.

b) As experiências e seus efeitos ora podem ser planejadas, ora podem ser incontroladas. Devem ser planejadas na ação.

c) Os processos que se desenvolvem na experiência escolar têm relevância; os métodos adequados justificam os processos. A escolha dos métodos recai na competência do professor.

Ainda sobre a importância de se considerar a experiência da criança, Gimeno Sacristán (2000) identifica o desafio da escola em conectar as experiências das crianças, levando-as à complexidade necessária para envolvê-las com os conhecimentos e com a cultura elaborada, que é necessária para a vida em sociedade. Essa aproximação entre a experiência e o conhecimento já era uma ideia defendida por Dewey (1967 al Gimeno Sacristán 2000, p. 42). Em suas palavras:

quando se concebe a educação no sentido da experiência: tudo o que pode se chamar estudo, seja aritmética, história, geografia ou uma das ciências naturais, deve ser derivado de materiais que a princípio caiam dentro do campo da experiência vital ordinária.

A concepção de experiência defendida por Dewey (1971) pode ser compreendida a partir do funcionamento orgânico, na tentativa de o ser humano conhecer o mundo e esboçar reações que nem sabe que tem (fome, sede, dor): é a experiência que, quando refletida, leva à aquisição de conhecimento e ao exercício consciente de suas ações.

As DCNEI (BRASIL, 2009a), referindo-se ao conjunto de práticas que buscam articular as experiências das crianças 
ao conhecimento científico-cultural, indicam a possibilidade de conexão da escola com a vida das crianças, despertando o interesse em aprender e buscar explicações para suas indagações.

Outro aspecto que marca as DCNEI é a visão de criança a ser contemplada no âmbito da educação:

\begin{abstract}
A criança, centro do planejamento curricular, é sujeito histórico e de direitos que se desenvolve nas interações, relações e práticas cotidianas a ela disponibilizadas e por ela estabelecidas com adultos e crianças de diferentes idades nos grupos e contextos culturais nos quais se insere. Nessas condições ela faz amizades, brinca com água ou terra, faz-deconta, deseja, aprende, observa, conversa, experimenta, questiona, constrói sentidos sobre o mundo e suas identidades pessoal e coletiva, produzindo cultura (BRASIL, 2009a, p. 6-7).
\end{abstract}

Essa concepção de criança como "ator social", com suas experiências no centro do planejamento, vem ao encontro de discussões e pesquisas acerca do protagonismo infantil nas atividades cotidianas das creches e pré-escolas (cf. EDWARDS et al., 1999; JAMES et al., 1998; SARMENTO, 2007; FARIA et al., 2002; entre outros pesquisadores).

Nessa perspectiva, a criança não é vista como objeto passivo e reprodutor da cultura do adulto: além de absorver a cultura do adulto, a criança também a cria, sendo possível observar, em recentes pesquisas realizadas com elas, a compreensão de uma cultura da infância.

Discutir a concepção de criança na esfera do currículo, da avaliação, do projeto e de todo trabalho pedagógico torna-se importante para guiar ações que ocorrem dentro da escola. Dessa forma, se a criança e suas experiências são o centro do planejamento curricular, não faz sentido algum criar projetos ou atividades que não correspondam ao seu interesse e não respeitem suas formas de ser e de estar no meio do qual fazem parte. Afinal, as crianças não são um projeto futuro; ao contrário, elas são, elas existem e agem sobre o meio em que vivem.

\title{
2.2.1. A participação da criança na avaliação
}

Aliadas ao currículo da escola e ao planejamento, a inserção e a participação do sujeito (criança, adolescente, adulto) na avaliação do próprio processo de ensino-aprendizagem repercutem em vários estudos sobre avaliação. 
Na perspectiva de verificar o processo de aprendizagem, e não somente o resultado, a avaliação formativa foi uma expressão proposta em 1967 por M. Scriven para se referir aos procedimentos utilizados pelos professores no sentido de regular o ensino às necessidades de aprendizagens observadas em seus alunos. Genthon (1992, apud BONNIOL; VIAL, 2001) discute que Scriven (1967, apud BONNIOL; VIAL, 2001) definiu em seus estudos dois tipos de função em relação à avaliação da aprendizagem: a avaliação somativa e a avaliação formativa. A avaliação somativa refere-se ao produto final. A avaliação formativa acompanha os processos e envolve as necessidades do sujeito.

Ao contrário da avaliação somativa, que se baseia na coleta de informações e elaboração de instrumentos que possibilitem medir o conhecimento, a avaliação formativa abrange o processo, assumindo um papel contínuo em relação à aquisição do conhecimento.

A avaliação formativa centra-se, portanto, em compreender o processo de aprendizagem do aluno. 0 erro e as dificuldades inerentes ao processo são objetos de estudo, pois revelam a compreensão ou representação elaborada pelo estudante com relação ao conhecimento.

Segundo Perrenoud (1996), a avaliação formativa faz com que o professor observe o aluno, a fim de compreender melhor como ele aprende e, depois, ajustar suas intervenções pedagógicas. Baseiase na perspectiva de uma regulação intencional, cujo objetivo seria determinar, ao mesmo tempo, o caminho já percorrido e aquele que resta a percorrer, visando à intervenção, para proporcionar os processos de aprendizagem em curso.

Nessa concepção, a avaliação deve constituir-se em oportunidade para que os sujeitos possam demonstrar o que sabem e como sabem. Somente assim o professor poderá intervir, mediar e orientar com consistência o aluno, como também poderá aprender junto nesse processo.

A inserção e a participação dos sujeitos no planejamento, no currículo, na gestão e em todos os âmbitos da educação é uma discussão guiada pelos estudos recentes. A avaliação formativa traz importante contribuição para a análise do processo de ensinoaprendizagem, convocando os sujeitos (professor, aluno) para a reflexão sobre o processo, seja pela autoavaliação ou coavaliação, diferentemente dos modelos mais tradicionais de avaliação, cujo foco estaria no resultado e em sua medida, isolando o processo. 
Em relação ao Paradigma Geral da Avaliação de Dispositivos Educativos, Rodrigues (1994) aponta três posicionamentos: objetivista, subjetivista e crítico, sendo que a autoavaliação se insere na perspectiva subjetivista, que traz o sujeito para o centro do processo de ensino-aprendizagem, priorizando o desenvolvimento individual. No posicionamento crítico, o sujeito sofre influência do contexto social e o influencia; neste sentido, pela coavaliação, o sujeito é motivado a avaliar as suas atividades, a escola e o que aprendeu. A coavaliação pode ser também uma relação de experimentação, confronto e investigação.

Álvarez Méndez (2002) defende a participação do aluno no processo avaliativo como um valioso feedback sobre o ensino e a melhor forma de conhecer o que eles realmente aprenderam, além de favorecer uma avaliação igualitária.

Nesse sentido, a avaliação é concebida como outra forma de aprender, de ter acesso ao conhecimento e continuar aprendendo. Trata-se de um processo dinâmico que poderá desencadear o replanejamento das atividades, a reflexão sobre as dificuldades e avanços em relação ao aprendizado e constante revisão do currículo.

Em relação à participação do sujeito no processo avaliativo, Abramowicz (1996) destaca que participação na avaliação é sinônimo de avaliação permanente, pois permite ao sujeito perceber-se, envolver-se e criticar-se durante o processo.

Saul (1999), por sua vez, baseando-se nas obras do autor e educador Paulo Freire, propõe a avaliação emancipatória, cujas referências teórico-metodológicas estão inseridas na avaliação democrática, a saber: a crítica institucional, a criação coletiva e a pesquisa participante.

A avaliação emancipatória caracteriza-se como um processo de descrição, análise e crítica de uma dada realidade, visando a transformá-la. A avaliação é situada em uma perspectiva políticopedagógica cujo interesse é emancipador, libertador e pretende provocar a reflexão, fazendo com que as pessoas envolvidas na ação educacional escrevam sua própria história (SAUL, 1999).

Em busca de uma avaliação contínua e que inclua a participação de todos os sujeitos envolvidos, Álvarez Méndez (2002) aponta a necessidade de criar e elaborar instrumentos de trabalho alternativos para desencadear o processo formativo dos que participam do processo educativo. Na Educação Infantil, como 
destacado anteriormente, foram criadas várias estratégias para acompanhar e avaliar a aprendizagem das crianças, tais como a utilização de fotos, pinturas, desenhos, gravação em áudio, entrevistas etc.

Oliveira-Formosinho e Azevedo (2008) relatam a experiência de realizar entrevistas com crianças para ter acesso ao que elas pensam sobre o portfólio de avaliação de suas aprendizagens.

Segundo as autoras, as entrevistas auxiliam a criança no processo de autoavaliação e de tomada de consciência dos seus processos de aprendizagem. Essa estratégia pode proporcionar a expressão de sua voz e lhes permite revisitar as suas experiências, dialogar, conhecer o seu percurso de aprendizagem e diferenciálo dos percursos dos outros (OLIVEIRA-FORMOSINHO; AZEVEDO, 2008).

A participação na avaliação leva os sujeitos (não somente as crianças) a se sentirem parte do processo, ao refletirem sobre o que aprenderam e como aprenderam. Isso faz com que o sujeito participante do processo avaliativo escreva e se torne autor de sua própria história (SAUL, 1999).

Nesse sentido, Oliveira-Formosinho (2007), ao discutir a pedagogia da infância, aponta para a pedagogia da participação (DEWEY, 1964; FREINET, 1970; BRUNER 1986; FREIRE, 1996, apud OLIVEIRA-FORMOSINHO, 2007), na qual propõe:

\footnotetext{
A pedagogia da participação centra-se nos atores que constroem o conhecimento para que participem progressivamente, através do processo educativo, da(s) cultura(s) que os constituem como seres sóciohistórico-culturais. A pedagogía da participação realiza uma dialogia constante entre a intencionalidade conhecida para o ato educativo e a sua prossecução no contexto com os atores, porque estes são pensados como ativos, competentes e com direito a co-definir o itinerário do projeto de apropriação da cultura que chamamos educação (OLIVEIRA-FORMOSINHO, 2007, p. 18-19).
}

A experiência de participação na avaliação deve ser permanente e integrada ao cotidiano educacional, como também abranger a família. Sabemos da resistência histórica da participação no contexto educativo, pelas linhas e concepções positivistas e tradicionais que ainda permeiam as práticas escolares. Também não há como pensar em participação popular se a estrutura que se diz "democrática" cria mecanismos próprios para inibir a manifestação das pessoas (FREIRE, 2001). Diante disso, devemos 
trazer a experiência da participação para vários setores da sociedade e da educação para que se lancem ao desafio junto com a escola.

Defendo, neste trabalho, que a participação não pode, portanto, ser convocada apenas no momento da avaliação de uma atividade, de um semestre, ou para ouvir a opinião do que mais se apreciou na escola. Esse conceito insere-se em um contexto educacional mais amplo, que se materializa na relação entre criança e adulto, no currículo praticado, durante a organização dos espaços, como também no tipo de educação para ela pensada.

\subsubsection{Observação e registro}

Embora se perceba que a observação e o registro são elementos fundamentais tanto para a elaboração da avaliação quanto para a reflexão do trabalho do professor, a mudança na prática avaliativa, com a incorporação desses dois aspectos de trabalho, não é simples. Ao contrário, requer uma mudança na concepção de educação e de criança (estar mais próximo a elas, escutá-las, propor diálogo etc.).

A observação e o registro escrito funcionam como procedimentos que auxiliam o planejamento e a avaliação, podendo também ter outros significados, pois, quando vivenciados pelos professores, oferecem apoio para organizar as suas ideias, rever as atividades propostas, acompanhar os avanços e dificuldades do próprio trabalho.

A publicação A paixão de conhecer o mundo, de Madalena Freire (1983), desvela a relação entre observar, planejar e registrar presentes no cotidiano de uma turma de crianças com idades que se aproximam dos 4 anos da Escola da Vila, em São Paulo. A autora narra uma passagem que ilustra tal relação:

\footnotetext{
Foi a partir da observação de algumas crianças que trabalhavam no parque espontaneamente, com areia, mexendo uma "sopa venenosa", que surgiu a sopa de macarrão. Voltamos à sala, devolvi em forma de estória o que tinha observado no parque, e no fim da estória perguntei se alguém já tinha feito uma sopa de verdade: (não?). E assim ficou combinado que no dia seguinte iríamos fazer uma sopa (de macarrão), e gritaram: "sem veneno", para tomarmos (FREIRE, 1983, p. 21).
}

0 processo de realização das atividades, os desenhos das crianças, as suas falas são observadas e registradas por escrito 
pela autora, para compor o diário da turma. Segundo Freire (1983, p. 77), "ele é também um importante 'documento', onde o vivido é registrado juntamente com as crianças. Nesse sentido educador e educandos, juntos, repensam sua prática".

Zabalza (1994) também aborda a importância do diário para o trabalho pedagógico, explicando que os "diários" fazem parte de enfoques ou linhas de pesquisa baseados em documentos pessoais ou narrações autobiográficas. Esse instrumento de orientação qualitativa adquiriu grande espaço na pesquisa educativa dos últimos anos.

A principal contribuição dos diários em relação a outros instrumentos de observação é que permitem fazer uma leitura sequencial dos acontecimentos, tornando possível analisar a evolução dos fatos (ZABALZA, 1994).

Na mesma direção que Freire (1983), Warschauer publica em 1993 o livro A roda e o registro: uma parceria entre professor, alunos e conhecimento. A autora conta a sua experiência como professora na década de 1980, ao propor a roda e o registro como uma dinâmica para trabalhar com temas de interesse das crianças. Warschauer (1993) propõe dois tipos de registro: um individual, que reflete sobre a prática em sala de aula; e outro, coletivo, que era construído com as crianças, colado na parede ou arquivado para utilização futura conforme o interesse da turma. Nessa perspectiva, o registro escrito permite que o professor acompanhe o processo de construção, representa a busca de sentido das atividades ocorridas, guarda a memória e desvela a lembrança do passado.

Tanto Freire (1983) como Warschauer (1993) utilizam as suas anotações em um instrumento denominado de "diário", cujos registros auxiliam na construção e organização do pensamento. A segunda autora referenciada indica, inclusive, que esse recurso abrevia a distância entre o ensino e a pesquisa, pois o professor se torna pesquisador de sua própria prática.

Warschauer (1993) explica que escrevia relatórios individuais das crianças durante o bimestre, destacando a sociabilidade, iniciativa e interesses demonstrados e lia com as crianças antes de entregar aos pais. Dessa forma, a avaliação fazia parte do trabalho diário com as crianças, faziam-se comentários e anotações e apontavam-se também dificuldades e avanços de cada uma delas.

Ocorre que, para registrar, é necessário observar como interagem as crianças, o que falam e pensam, assim como 
interpretar o seu silêncio para acompanhar as suas descobertas e aprendizagens. Weffort (1995) destaca que observar uma prática pedagógica não significa vigiá-la, mas sim fazer vigília por ela, permanecer acordado por ela.

Nessa mesma perspectiva, Jablon e colaboradores (2009) realizam uma pesquisa a respeito das observações que alguns professores elaboraram sobre as crianças pequenas em contexto educacional e verificam que a observação tem "poder", já que representa a sua ideia (ou seu olhar) sobre o outro sujeito.

Segundo os autores, a observação sobre o outro traz, em nossa cultura, valores e expectativas sobre as pessoas. Eles apontam que a observação e o registro têm, realmente, esse lado subjetivo, mas que há maneira de isolá-lo, na medida em que o professor ou o observador descreva o fato ou o acontecimento sem interpretação ou julgamento. Assim, sugerem que os professores dividam seus registros em duas partes: de um lado, a descrição da observação e, do outro, as interpretações sobre o acontecimento (JABLON et al., 2009).

0 exercício de registrar o cotidiano das crianças é um grande desafio para o professor. Ostetto (2008) explica que, antes, é necessário refletir sobre como observamos as ações, reações e indagações das crianças.

Durante o trabalho cotidiano, o professor está constantemente em interação com as crianças e, por isso, deve estar atento às suas observações e ao próprio olhar. Nesse sentido, Ostetto (2008) sugere algumas perguntas diante da ação de observar: como olhamos? Será que buscamos algum padrão de sujeito? Sem nos darmos conta, muitas vezes temos um olhar paralisado e repetitivo, sendo necessária uma reflexão sobre o que olhar e observar.

A utilização de critérios ou um ponto de partida auxilia na observação do professor sobre a realização das atividades pelas crianças. Por exemplo, durante uma atividade de parque livre, o professor pode ter como critério de observação a sociabilidade entre as crianças e sua autonomia (ou não) na resolução de conflitos, o que representa para a criança pequena um avanço significativo em seu desenvolvimento ao resolver um conflito pelo uso de diálogo, sem o auxílio do professor (VYGOTSKY, 1930-5).

0 ato de observar também pode ser livre, sem, necessariamente, haver um foco; por exemplo, por vezes, presenciamos conversas entre as crianças que buscam "ensinar" 
umas às outras como realizar alguma tarefa. Esse diálogo pode trazer indícios de aprendizagem, sem termos um foco de observação em mente.

Atualmente, além do registro escrito, discutem-se variadas formas de registro, tais como: fotografias, filmagens, gravação em áudio, desenhos, pinturas etc., compondo assim a documentação sobre o trabalho pedagógico e as experiências vivenciadas pelas crianças.

\section{Metodologia}

0 presente estudo enquadra-se no tipo pesquisa-ação, envolvendo esta pesquisadora, as gestoras e professoras de duas unidades de Educação Infantil e as crianças. A metodologia adotada seguiu a concepção definida por Michel Thiollent (2004), e, para o autor, a pesquisa-ação tem vínculo estreito com uma determinada ação ou com a resolução de um problema coletivo, no qual os pesquisadores e os participantes representativos da situação estão envolvidos de modo participativo.

A pesquisa ocorreu durante o ano letivo de 2012 em duas EMEls localizadas na região do Jaraguá, zona oeste do município de São Paulo. Neste trabalho, apresentarei apenas um recorte dos dados obtidos em uma das escolas. 0 local da pesquisa e as professoras receberam nomes de flores e árvores, as crianças foram identificadas com nome próprio, mas também fictício, em respeito ao anonimato dos participantes e da escola, conforme os documentos encaminhados ao comitê de ética da Pontifícia Universidade Católica de São Paulo. Na EMEI Cerejeira, participaram seis professoras e uma coordenadora pedagógica. A coleta de dados envolveu diário de campo, documentos (relatórios de avaliação) e gravação em áudio e vídeo. As professoras realizaram entrevistas com as crianças e utilizaram diários de campo (cadernos de registro).

A EMEI Cerejeira possui projetos pedagógicos que trazem a participação da criança para o centro das atividades propostas. São realizadas assembleias, ou conselho mirim, com a intenção de ouvir a opinião das crianças sobre o que elas desejam para a realização de uma determinada festa, para a aquisição de novos brinquedos, sobre os projetos pedagógicos; e seus questionamentos modificam as propostas. Entretanto, a criança não se encontrava no centro da escrita do relatório de avaliação, 
pois havia uma descrição detalhada dos projetos desenvolvidos pelas turmas, mas poucos registros sobre a interação da criança no projeto. Segundo Thiollent (2004), quando investigamos o tema junto com os participantes da pesquisa, verificamos que outras necessidades ou preocupações surgem durante o percurso. 0 autor alerta que tais problemas têm que ser definidos de modo bastante prático e claro aos olhos de todos os participantes, porque a pesquisa será organizada em torno da busca de soluções (THIOLLENT, 2004, p. 52).

Assim, antes de abordar o tema da participação da criança na avaliação, a pesquisa mudou de "rumo": direcionando o olhar para a participação das crianças nas atividades cotidianas e na construção do currículo, provoquei as professoras a analisar a sua prática com as crianças, observar a participação delas e a importância do registro escrito. Assim, a escrita do relatório passou a focar a criança, cujo interlocutor, neste caso, são seus familiares, preocupando-me com a leitura dos registros e seu potencial de compreensão para as famílias. Com a utilização das entrevistas, buscamos dar voz à criança no próprio instrumento de avaliação.

\section{Apresentação de resultados}

\section{A criança no centro da escrita do relatório de avaliação}

Durante os primeiros encontros com as professoras da EMEI Cerejeira, constatei que a escrita do relatório estava mais voltada para o projeto desenvolvido do que para a criança, foco que foi sendo alterado no decorrer do trabalho. Tal opção poderia ser decorrente dos critérios adotados para a escrita, uma vez que eles eram extraídos dos próprios projetos realizados com as crianças. A professora Paineira, por exemplo, destacou a ideia de como surgiu o projeto realizado com a turma:

Nesse segundo semestre, a turminha se interessou pela pesquisa de animais... Tudo começou ainda no semestre passado, quando encontramos a "paquinha" no tanque de areia da escola. A partir daí a ida ao parque sempre foi muito mais do que tempo de brincar, as pesquisas não paravam e toda hora alguém achava um bichinho novo e junto com ele vinham muitas perguntas $e$ hipóteses (...).

Percebeu-se, então, que esse ponto de partida do projeto - o interesse das crianças em pesquisar os animais encontrados no 
parque - tornou-se critério de avaliação. Em seguida, a professora destacou que elas realizaram pesquisas em livros de ciências, discutiram os temas nas rodas de conversa, criaram histórias e registros ao redor do assunto.

O fato de destacar, no critério de avaliação, a ideia e o surgimento do projeto demonstrou a preocupação com a escuta da fala das crianças durante o processo de ensino-aprendizagem na escola. A professora apontou também, no relatório, o andamento do projeto que abrange a escola toda - a diversidade cultural e as brincadeiras produzidas pelo artista plástico brasileiro Ivan Cruz: “(...) As Artes e as brincadeiras também fizeram parte dos nossos dias nesse semestre: através das obras de Ivan Cruz pudemos unir o prazer de brincar (e conhecer novas brincadeiras) com o fazer artístico (...)."

A partir da discussão sobre o critério de avaliação, as professoras argumentaram sobre como as crianças realizavam as atividades com relação aos projetos, os avanços e as dificuldades, as intervenções e uma entrevista sobre o que cada uma delas aprendeu com o projeto.

Cada professor tem um estilo de escrita. Verifiquei, por exemplo, que a professora Paineira escrevia de forma menos formal, enquanto a professora Jabuticabeira relatava os objetivos gerais do trabalho, tais como estavam no projeto oficial da escola. Entretanto, os dois trechos comunicavam a ideia do trabalho desenvolvido com as crianças, para que o leitor percebesse o ponto de partida do registro e do processo de ensino-aprendizagem.

Em relação às atividades, a segunda professora relatou várias experiências desenvolvidas durante o semestre:

No primeiro semestre o trabalho teve o foco nas relações entre si e com os colegas da turma, devido à dificuldade de alguns alunos em se relacionarem e respeitarem a singularidade de colegas da turma (...).

No segundo semestre continuamos desenvolvendo atividades com jogos e brincadeiras como futebol, pular corda (...).

(...) As crianças apreciaram obras de Ivan Cruz, pintor carioca que retrata brincadeiras de sua infância (...).

Observei que a necessidade da turma da professora Jabuticabeira era em relação à interação das crianças, trabalhando assim a diversidade e a inclusão, conforme discutido 
anteriormente. Percebi, também, o trabalho com as obras de Ivan Cruz, que novamente apareceram no critério, relacionadas ao trabalho pedagógico.

0 trabalho desenvolvido com os projetos apareceu no texto de forma superficial e o leitor teria dificuldade para compreender como surgiu sua ideia central ou seu tema. Ficariam sem respostas, ainda, as questões: por que as crianças apreciaram a obra do pintor Ivan Cruz? Quais os temas das obras desse artista?

A linguagem do movimento implica, normalmente, o surgimento de várias ações e atividades; embora a professora tenha escrito que trabalhou com as regras, faltou informação de outras atividades que devem ter sido trabalhadas com a turma, bem como sua ligação com o projeto.

As professoras Flamboyant e Amoreira, que também dividiam a mesma turma, fizeram o relatório no mesmo formato. No excerto a seguir, a premissa "no momento das histórias" também ficou vaga para a apresentação de uma avaliação contínua.

(...) No momento das histórias ela ouve com atenção e até faz perguntas no meio da história e depois participa do reconto.

(...) Esse trabalho realizado com alguns artistas, como: Ivan Cruz, Vik Muniz, mestres do Impressionismo (exemplo: Monet), Kaith Haring, entre outros, tem ampliado o repertório da Fabiana e refletido no aperfeiçoamento de seus registros e vocabulário.

Neste trecho apontei a ausência de determinadas informações.

Quadro 1 - Intervenção sobre os registros - EMEI Cerejeira

Pesquisadora: "Vocês conseguiram enxergar a criança? Verifiquei a ausência de algumas informações: quais foram as histórias trabalhadas? Essas histórias tiveram relação com os projetos? Qual foi o objetivo a ser alcançado? Por que surgiu o trabalho com os artistas?"

Flamboyant: Realmente esses detalhes fazem falta para quem não estava na situação."

Durante os encontros, constatamos a dificuldade das professoras em realizar os registros e a necessidade de se discutir a argumentação como uma prática de organização textual, para que o professor, com o uso de premissas, argumentos, contraargumentos e solução (BRONCKART, 1997), possa organizar os 
registros e refletir sobre eles, já que para argumentar é necessário ter suporte para defender uma ideia. Essa organização textual implica o registro das intervenções realizadas pelo professor nas aprendizagens e as dificuldades ocorridas no processo de ensino-aprendizagem. A sequência argumentativa na planificação de textos proposta por Bronckart (1997) foi utilizada pela pesquisadora Colasanto (2007) na elaboração de relatórios de avaliação na Educação Infantil.

Assim, durante o processo de construção do relatório, verificamos que, com o apoio das observações e do registro escrito, a criança passa a ser o centro da produção escrita. Os jogos e as brincadeiras estavam presentes no trabalho com as crianças da EMEI Cerejeira. Analisamos, nos registros, como essas atividades apareciam e qual o envolvimento das crianças. As professoras Flamboyant e Amoreira registraram o processo de inclusão da aluna Marcela, por exemplo:

Com o projeto "Resgate das Brincadeiras", a Marcela tem surpreendido a todos! Ela não deixa de participar de nada. Brinca de amarelinha, corda, esconde-esconde, entre outras (...) Enfim a Marcela nos faz esquecer que ela tem uma deficiência física, visto que essa deficiência não a impede de viver a sua infância de maneira autônoma e feliz.

(...) Certa vez estávamos em uma atividade do campo (dirigido) e a professora Jabuticabeira percebeu que a Marcela queria pular corda de outro jeito, então eu (professora Amoreira) segurei a sua mão e a professora Jabuticabeira bateu corda para nós duas. Foi uma festa! Ela adorou o momento.

A participação das crianças e o envolvimento de todas nos jogos e brincadeiras foram alguns dos aspectos observados pelo trabalho pedagógico da EMEI Cerejeira, onde a todo momento alguma turma desenvolvia esse tipo de atividade em sua área externa.

Pelo trecho do relatório escrito pelas professoras Flamboyant e Amoreira, pude perceber que Marcela, mesmo tendo uma dificuldade física, participava das brincadeiras com a turma e que as professoras auxiliaram a criança quando perceberam que ela desejava realizar algum movimento com apoio. Essa interação foi importante para que a criança brincasse e se desenvolvesse.

As professoras enfatizaram, nesse relato, a participação de Marcela nos jogos e brincadeiras para que a família acompanhasse o seu desenvolvimento, pois, na escola anterior, que ela não gostava de frequentar, quase não participava desses momentos. 
0 jogo e as brincadeiras são aspectos essenciais a serem observados em EMEls porque oferecem momentos de integração e aprendizagem também. Analiso, no excerto a seguir, esses dois aspectos, que apareceram no relatório da professora Jabuticabeira sobre uma mesma criança:

\section{(...) Neste semestre, o Ryan continua brincando muito com as} crianças, muito colaborador com os colegas, principalmente com o aluno com necessidade especial de visão, o Rogério. Ele o inclui constantemente nos jogos e brincadeiras nos diferentes espaços da escola. No jogo de futebol sempre passa a bola para os colegas, para que todos participem da brincadeira.

(...) Gosta muito de jogos de mesa, como xadrez, quebra-cabeça e outros jogos de construção. No início do ano começou a aprender e entender como as peças do jogo de xadrez se movimentam, cria estratégias de jogo como usar a rainha, pois captura a peça do adversário (...)

Nesse relato percebe-se a função do jogo em integrar as crianças, visto que Ryan brincava junto com os colegas e procurava integrar um aluno com dificuldade visual na atividade. Essa ação demonstrou seu papel mediador entre o colega e o jogo. Outro aspecto que observei foi o repertório que a escola pode oferecer às crianças em relação aos jogos e brincadeiras que, às vezes, diferem dos encontrados no contexto familiar, como os jogos de tabuleiro.

Verifiquei que Ryan tinha começado a aprender a jogar xadrez no início do ano e que, naquele momento, já criava suas próprias estratégias. Isso demonstrou que as crianças na escola, além de ampliar repertórios de jogos e brincadeiras, aprendem com eles novas formas de brincar, elaboram regras e são incentivadas na construção do conhecimento.

A evolução de Jonathan em seu desenvolvimento também foi registrada pelas professoras Figueira e Eucalipto:

(...) No início, o mesmo não se atentava na explicação da brincadeira, nem na brincadeira propriamente dita: ficava disperso, sempre conversando com o Renato, ou com quem estivesse ao seu lado, não conseguindo se concentrar. Com o passar do tempo, através de um trabalho pautado em muitas conversas e, à medida que foi descobrindo o prazer de participar das brincadeiras dirigidas, o mesmo passou a interessar-se mais, muitas vezes até mesmo dando sugestões sobre qual brincadeira a turma poderia fazer (sua preferência pessoal é o futebol). 
A brincadeira na escola, quando organizada pela professora (campo dirigido), procurou ampliar o repertório, apresentando intencionalidade em relação a algum aspecto do desenvolvimento infantil. Geralmente, nos campos dirigidos foram desenvolvidos jogos de regras, pois essa competência sempre fez parte do planejamento da professora e pode, por exemplo, se desenvolver a partir de um jogo relacionado com o projeto.

Nesse caso, observei que Jonathan não demonstrava interesse pelas brincadeiras. Embora a professora não tenha argumentado detalhadamente sobre as intervenções realizadas para que ele se envolvesse na atividade, observei que, à época do relatório, a criança se envolvia e revelou preferência por jogar futebol.

A organização das salas de aula em cantos também facilitou a observação, por parte da professora, das brincadeiras desenvolvidas pelas crianças, dispostas em pequenos grupos. Diferentemente, da proposta de campo dirigido, nos cantos as crianças escolhiam onde desejavam brincar e com quais colegas, como registraram as professoras Flamboyant e Amoreira a respeito do aluno Douglas:

Nos cantinhos propostos na sala de aula, o Douglas demonstra grandes conquistas, costuma ficar concentrado em diversas atividades que ele mesmo opta. Por exemplo, há momentos em que ele brinca com uma boneca específica (que ele gosta muito), demonstra afeto por ela, conversa o tempo todo com essa boneca etc. Em outro momento ele fica concentrado "lendo" gibis, depois brinca de carrinhos. 0 que tem surpreendido muito nestas últimas semanas é vê-lo bastante interessado em desenhar no espaço do registro (...)

Partindo do pressuposto de que a avaliação adequada é aquela em que o professor compara a criança com ela mesma (SÃO PAULO, 2007a, b), observei que as professoras fizeram uma análise sobre as preferências de brinquedos e como Douglas brincava nos cantos, comparando-o consigo mesmo. Ou seja, destacaram em seu relatório a sua concentração no faz de conta, a opção pelos cantos das bonecas, gibis e carrinhos, sem distinção ou preconceito de gênero, como também evidenciaram o seu interesse pelo espaço do registro, demonstrando avanço.

0 interesse da criança em registrar significou um avanço em relação ao seu interesse pela escrita. Conforme os estudos de Vygotsky, a criança percebe que pode representar primeiramente suas ideias pelos desenhos, para, então, partir para 
a representação da escrita. 0 interesse de Douglas em realizar desenhos no canto de registros pode revelar essa necessidade de representar os acontecimentos e as pessoas com quem convive diariamente.

Considerando a brincadeira como eixo central da Educação Infantil, verifiquei que a observação das professoras sobre como a criança brincava, como interagia com os colegas e como aprendia poderia ser fonte de informação e registro sobre seu desenvolvimento.

Durante os registros dos relatórios de avaliação, a aquisição da linguagem escrita apareceu de diversas formas: pelo incentivo da escrita do nome, pelas rodas de histórias, pelos textos coletivos etc. Verifiquei, ainda, que na EMEI Cerejeira as professoras participantes desta pesquisa procuravam trabalhar a escrita de forma significativa para a criança, e seu processo costumava aparecer nos relatórios de avaliação das crianças, como neste trecho, extraído do relatório da professora Paineira sobre o aluno Luiz:

A professora também planejou atividades como "caça ao nome" e "amigo secreto", no momento da chamada, visando incentivar a leitura/reconhecimento do nome próprio e do nome dos amigos. 0 Luiz também teve muitos progressos nessas atividades e passou a reconhecer a escrita do seu nome e o de quase todos os amigos. Também, incentivado pela educadora a nomear as suas produções e atividades, passou a escrever o nome completo (nome e sobrenome) sem auxílio do crachá.

Nesse extrato do relatório de avaliação, observei que a professora Paineira exemplificou duas atividades realizadas com a turma e que trabalham com a escrita do nome; são elas: "caça ao nome" e "amigo secreto". Durante essas atividades, a professora observou e registrou os avanços do Luiz no reconhecimento do seu nome e o dos colegas.

A professora também apontou no relatório que ensina o menino a utilizar a escrita de seu nome, neste caso para nomear as suas produções. Tais ações revelaram que o processo de ensinoaprendizagem da escrita estava relacionado com a sua função social, pois o nome não foi apresentado à criança a partir de cópias ou repetição, mas de atividades significativas.

Assim, foi possível acompanhar o processo de ensinoaprendizagem da criança em relação à escrita, visto que muitas 
delas aparecem em casa com tal conhecimento em processo de construção. A família pode acompanhar esta e outras conquistas pelo relatório individual de avaliação, como se verifica no que as professoras Figueira e Eucalipto elaboraram sobre o aluno Jonathan:

(...) Na linguagem escrita, no trabalho com seu nome, diferente do semestre anterior, em que apenas escrevia JONATAA, demonstra apropriação do nome completo. Agora escreve Jonathan Perera, faltando ainda algumas letras. Porém, durante a escrita do seu nome, vale ressaltar que ele fez uso do alfabeto que está disposto na sala. Quando se esquece de alguma letra levanta da cadeira, olha o alfabeto e diz: "Ah! Lembrei" e volta escrever seu nome.

As professoras Figueira e Eucalipto descreveram o processo de desenvolvimento da escrita de Jonathan escrevendo o próprio nome e sua estratégia em olhar o alfabeto da lousa quando precisava se lembrar de alguma letra. A escrita do nome é uma das aprendizagens desenvolvidas pelas crianças nas EMEls, sendo que o registro desse processo faz com que os familiares e professores da série seguinte verifiquem os avanços ou dificuldades da criança.

Outras atividades foram realizadas para que as crianças tivessem contato com a leitura e a escrita, tal como a Sessão de Leitura Simultânea - Projeto Entorno - (FVC, 2009), biblioteca móvel, roda de história etc. Nas salas, verifiquei que havia estantes de livros na altura das crianças, para que tivessem acesso fácil a eles. As professoras Figueira e Eucalipto demonstraram, também, reconhecer o envolvimento do aluno com a leitura em casa, como no relatório sobre Renato, a seguir:

(...) percebemos também que a família adora ler e participar das atividades oportunizadas pela escola. Quando enviamos para casa a Maleta de Leitura, que foi atribuída pela turma Maleta dos Sonhos com o objetivo de levar história e magia para a sua casa... o Renato fica radiante, e, quando não é sua vez de levá-la, pede para levar um livro do canto de leitura.

No registro inicial, as professoras sinalizaram que a família lia para Renato e participavam das atividades proporcionadas pela EMEI. Essa integração escola e família valorizou o trabalho e o interesse do aluno pelas histórias. Observei que existia um trabalho em parceria com a família em relação à leitura de histórias, pela estratégia denominada "Maleta dos Sonhos", na qual as crianças levavam o livro para casa. Nesse trecho do relatório foi possível 
verificar, pelo registro das professoras, que essa criança também era incentivada pela família, já que levava para casa os livros do "canto de leitura".

\section{A criança participa da própria avaliação}

Desde o início desta pesquisa, propus aos grupos de professoras das duas escolas a participação da criança na própria avaliação, com a intenção de dar voz a ela sobre o que faz na escola. As professoras aceitaram a proposta e optaram pela entrevista com as crianças sobre os projetos e atividades, sendo que cada grupo de professoras elaborou suas questões e organizou as crianças de formas diferentes.

Na EMEI Cerejeira, no final do segundo semestre de 2012, a professora Paineira apresentou um espaço reservado no relatório de avaliação para a "autoavaliação da criança" e outro reservado para a família.

Durante a realização dos cantos, a professora conversou com as crianças individualmente e apresentou a seguinte questão: "0 que você aprendeu com o 'Projeto Bichos'?". As falas das crianças foram registradas no caderno da professora e, posteriormente, digitadas no relatório de avaliação, que seria entregue a seus familiares.

Quadro 2 - Avaliação das crianças

Turma da Professora Paineira - EMEI Cerejeira

Gabriela: "Eu aprendi que o bicho-preguiça dorme de cabeça para baixo. E que o lobo-guará tem pernas longas".

Rodolfo: "Tem animais que nascem do ovo: o filhote do pato, do cocoricó e o jacaré".

Willian: "Aprendi que o leão tem ossos. Formiga não tem ossos. Cobra tem ossos. Lobo-guará tem ossos e onça tem ossos".

Jean: "Que os dinossauros botam ovos. E que o vulcão tem aquela chaminé que pega fogo e queima tudo o que tem na frente. Eu aprendi que quem nasce do ovo não mama no peito da mamãe e quem bota ovo não é mamífero".

Verifiquei que a professora realizou, individualmente, uma entrevista com as crianças, a fim de que elas comentassem o que 
aprenderam durante o "Projeto Bichos". Cada criança comentou sobre um animal ou um aprendizado diferente. Esse aprendizado foi evidenciado pela utilização de conhecimento científico-cultural que a criança utilizou em sua fala para, assim, demonstrar o que aprendeu com relação ao projeto.

Esses registros revelaram o potencial das crianças em aprender e em avaliar o que aprenderam, ou seja, aspectos da autoavaliação do processo de ensino-aprendizagem. Devo frisar que a autoavaliação da criança pôde, ainda, ser aproveitada para que o professor avaliasse o seu trabalho com a turma.

Um aspecto que se repetiu nas falas das crianças tinha relação com os animais mamíferos e ovíparos (botam ovos); os animais vertebrados (animais que possuem ossos) e invertebrados (animais que não possuem ossos). Parece que esse conhecimento ficou compreensível e claro para elas; foram, também, citados outros aspectos da natureza, tais como vulcões em erupção e as pernas longas do lobo-guará.

Dar voz à criança na própria avaliação, escutar sua opinião e sua impressão sobre o trabalho realizado na escola é, assim, um aspecto importante para as escolas de Educação Infantil, pois evidencia uma proposta de participação.

O fato de a criança poder avaliar o que aprendeu na escola, dizer sobre suas preferências implica a preparação de um espaço, para que ela veja as suas produções. Essa ação requer um momento de atenção especial e individual com cada criança, e ela precisa estar disposta a conversar com o professor sobre o assunto.

\section{Considerações finais}

As professoras da EMEI Cerejeira já elaboravam relatórios individuais de avaliação. Entretanto, neles predominavam a escrita sobre os projetos realizados com as crianças, e não o processo de desenvolvimento da criança e o trabalho desenvolvido com ela. Apresentavam observações gerais sobre as crianças. Durante a pesquisa, as professoras centraram suas observações em cada uma delas, passando a registrar suas falas, ações e seu desenvolvimento.

A organização textual da sequência argumentativa proposta por Bronckart (1997/2003) auxiliou as professoras nos registros escritos, principalmente para argumentar e contra-argumentar, 
sendo imprescindível o registro, para que as professoras pudessem convencer seus interlocutores sobre a avaliação que realizavam. Assim, no relatório, os registros apareceram no formato de exemplos, tanto para relatar algum acontecimento quanto para anotar a "fala" da criança em determinada situação, revelando ao interlocutor uma curiosidade, um aprendizado ou uma dificuldade dela.

Em síntese, a própria organização textual do relatório se constituiu como grande desafio a ser superado na escola. A questão poderia ser resumida desta forma: "Será que registramos por escrito como são propostas as atividades, as intervenções, o que as crianças falam e como aprendem?". As professoras avaliaram a própria dificuldade em relação aos registros e solicitaram auxílio. Essa atitude facilitou a pesquisa, pois pude contar com a colaboração e dedicação das professoras durante o trabalho. Assim, cada criança se tornou o sujeito principal da escrita do relatório; a criança que participa, interage, aprende e ensina.

Outro aspecto comum encontrado nos relatórios de avaliação foi o fato de a professora colocar-se no papel de espectadora da ação, sendo que, na prática cotidiana, elas interagem o tempo todo com as crianças. Quando as professoras passaram a apontar, no relatório, suas intervenções pedagógicas, elas não só fortaleceram seus argumentos na avaliação, como também mostraram que o processo de ensino-aprendizagem não ocorre por acaso ou naturalmente.

Da mesma forma, nosso processo de ensino-aprendizagem como professores e pesquisadores não acontece sem esforço: 0 estudo sobre a produção de relatórios, que as equipes das duas escolas compartilharam comigo, mostrou que o registro pode também contribuir para a própria formação do professor, na medida em que o coordenador pedagógico possa utilizá-lo para problematizar as intervenções e mediações entre professora e criança, na resolução de algum conflito, na proposta de alguma atividade, buscando o crescimento e aprimoramento do trabalho.

Observar o currículo praticado na escola de Educação Infantil foi outro aspecto importante para resgatar, pela produção escrita, as vivências, as falas e o desenvolvimento de cada criança no cotidiano das atividades realizadas. Trazer o protagonismo das crianças durante as atividades para os registros é ainda um desafio permanente para as professoras, porque envolve a prática habitual em registrar as próprias observações, a organização de 
um grupo grande de crianças (são 35 crianças por adulto) e o acompanhamento do processo de aprendizagem de cada criança, que é singular.

Verificamos que dar a voz à criança na própria avaliação articulava-se com a prática democrática desenvolvida no interior da escola, na qual as crianças podiam opinar sobre as atividades de sua preferência. Mas concluímos, com a pesquisa, que esse exercício deveria ocorrer com frequência e não apenas no final de cada semestre.

Devo reforçar que as entrevistas realizadas com as crianças tiveram perguntas diferentes, uma vez que as professoras tiveram autonomia para decidir o que conversar com elas.

Os questionamentos que as professoras da EMEI Cerejeira realizaram se aproximaram da autoavaliação, pois fizeram perguntas pontuais sobre os projetos de trabalho, principalmente o projeto sobre animais. Mesmo assim, percebi que a maioria das crianças disse o que aprende na escola de uma forma geral, sendo que algumas delas relataram lembranças de outros projetos e vivências. Assim, acabamos concluindo que a autoavaliação sobre determinado assunto deve fazer parte de cada projeto de trabalho, devendo ser realizada periodicamente e não apenas no final do projeto ou semestre.

Dar voz para a criança expressar a sua opinião sobre a escola e atividades realizadas também é um espaço importante, conforme aprendemos com Freire (1983, p. 45): "O sujeito pensante não pode pensar sozinho; não pode pensar sem a co-participação de outros sujeitos no ato de pensar sobre o objeto". Quando as crianças estavam com o caderno de registro em mãos, elas descreviam o que tinham feito na escola, se o desenho era com canetas, por onde haviam começado a produção, se achavam bonito ou feio. Observei que, ao questioná-las sobre o processo, o diálogo se fortalecia com a explicação e a opinião pessoal com relação às atividades.

Esse espaço de reflexão permitiu a tomada de consciência, que surgiu na inserção do sujeito a respeito de sua história, não como espectador ou figurante, mas como ator principal (FREIRE, 1983). Ao participar da avaliação de suas aprendizagens, a criança acabava refletindo sobre suas escolhas e as atividades realizadas. 


\section{REFERÊNCIAS}

ABRAMOWICZ, M. Avaliando a avaliação da aprendizagem: um novo olhar. São Paulo: Lúmen, 1996.

ABRAMOWICZ, M., et al. Currículo e Avaliação: uma articulação necessária - textos e contextos. Recife, PE: Centro Paulo Freire/Bagaço, 2006.

ÁLVAREZ MÉNDEZ, J.M. Avaliar para conhecer, examinar para excluir. Porto Alegre, RS: Artmed, 2002.

ARROYO, M.G. Currículo, território em disputa. Petrópolis, RJ: Vozes, 2011.

BARBOSA, M.C. Projeto de cooperação técnica MEC e UFRGS para construção de Orientações Curriculares para a Educação Infantil. Relatório de pesquisa, mapeamento e análise das propostas pedagógicas municipais para a Educação Infantil no Brasil. Brasília: MEC/SEB, 2009.

BONNIOL, J.J.; VIAL, M. Modelos de avaliação: textos fundamentais. Porto Alegre, RS: Artmed, 2001.

BRASIL. Lei $N^{0} 12.796$, de 4 de Abril de 2013. Altera a Lei no 9.394, de 20 de dezembro de 1996, que estabelece as diretrizes e bases da educação nacional, para dispor sobre a formação dos profissionais da educação e dar outras providências. Brasília: MEC/SEF, 2013.

- Diretrizes Curriculares Nacionais para a Educação Infantil. Alterada pela Resolução nº 5 - 17/12/2009. Brasília: MEC/CEB, 2009a.

Resolução CEB N ${ }^{0}$. 1, de 7 de abril de 1999. Institui as Diretrizes Curriculares Nacionais para a Educação Infantil. Brasília: MEC/CEB, 1999.

- Referencial Curricular Nacional para a Educação Infantil. Secretaria de Educação Fundamental. Brasília: MEC/ SEF, vols. I, II, III, 1998a.

- Lei de Diretrizes e Bases da Educação Nacional. Lei n9.394/96, de 20 de Dezembro de 1996. 
BRONCKART, J.-P. (1997). Atividade de linguagem, textos e discursos: por um interacionismo sócio-discursivo. Tradução de Anna Rachel Machado e Péricles Cunha. São Paulo: Educ, 2003

CERISARA, A.B. O Referencial Curricular Nacional Para a Educação Infantil no contexto das reformas. Educação \& Sociedade. Campinas, SP, vol. 23, n. 80, p. 326-345, setembro/2002.

COLASANTO, C.A. A linguagem dos relatórios: uma proposta de avaliação para Educação Infantil. 2007. 105p. Dissertação (Mestrado em Linguística Aplicada e Estudos da Linguagem) - LAEL, Pontifícia Universidade Católica de São Paulo. São Paulo, 2007.

C.A. Avaliação na Educação Infantil: a participação da criança. 2014. 198p. Tese (Doutorado em Educação: Currículo), Pontifícia Universidade Católica de São Paulo. São Paulo, 2014.

CURY, C.R.J. Direito à Educação: direito à igualdade, direito à diferença. Caderno de Pesquisa, nº. 116, p. 245-262, julho/2002.

DEWEY, J. Experiência e educação. São Paulo: Companhia Editora Nacional, 1971.

- Democracia e Educação: introdução à filosofia da educação - $3^{a}$ ed. São Paulo: Companhia Editora Nacional, 1959.

DIDONET, V. A Avaliação na e da Educação Infantil. 2012. Disponível em: <http://www.mpsp.mp.br/portal/page/ portal/Pesquisa_Avancada>. Acesso em: 11 jun. 2014.

EDWARDS, C.; FORMAN, G.; GANDINI, L. As cem linguagens da criança. A abordag'em de Reģgio Emilia na educação da primeira infância. Porto Alegre, RS: Artmed, 1999.

FARIA, A.L.G. de; DEMARTINI, Z.B.F.; PRADO, P.D. (Orgs.) Por uma cultura da infância: metodologias de pesquisa com crianças. Campinas, SP: Autores Associados, 2002. 
FREIRE, M. A paixão de conhecer o mundo. São Paulo: Editora Paz e Terra, 1983.

FREIRE, P. Pedagogia do Oprimido. $40^{a}$ ed. Rio de Janeiro: Paz e Terra, 2005.

Cortez, 2001.

Política e educação: ensaios, $5^{a}$ ed. São Paulo, Pedagogia da autonomia: saberes necessários à prática educativa. São Paulo: Paz e Terra, 1996.

. Extensão ou comunicação? $7^{\mathrm{a}}$ ed. Rio de Janeiro: Paz e Terra, 1983.

FREITAS, L.C. de. Os reformadores empresariais da educação e a disputa pelo controle do processo pedagógico na escola. Educação \& Sociedade, Campinas, SP, V. 35, nº.129, p. 1085 1114, 2014.

FUNDAÇÃO VITOR CIVITA. Projeto Entorno. São Paulo: Editora Abril, 2009. 28

GIMENO SACRISTÁN, J. O currículo: uma reflexão sobre a prática. Tradução de Ernani F. da F. Rosa - $3^{a}$ ed. Porto Alegre: Artmed, 2000.

HOFFMAN, J. Avaliação na pré-escola: um olhar sensível e reflexivo sobre a criança. Porto Alegre, RS: Mediação, 1996.

JABLON, J.R.; DOMBRO, A.L.; DICHTELMILLER M.L. O poder da observação: do nascimento aos 8 anos. $2^{a}$ Ed. Porto Alegre, RS: Artmed, 2009.

JAMES, A.; JENKS, C.; PROUT, A. Theorizing Childhood. Cambridge: Polity Press, 1998.

OLIVEIRA-FORMOSINHO, J. Pedagogia(s) da infância: reconstruindo uma práxis de participação. In: OLIVEIRAFORMOSINHO, J.; KISHIMOTO, T.M.; PINAZZA, M.A. (Org.). Pedagogia(s) da Infância - Dialogando com o passado, construindo o futuro. Porto Alegre, RS: Artmed, 2007, p. $13-36$. 
OLIVEIRA-FORMOSINHO, J.; AZEVEDO A. A documentação da aprendizagem: a voz das crianças. In: OLIVEIRAFORMOSINHO, J. A escola vista pelas crianças. Porto, Portugal: Porto Editora, 2008, p. 117-143. (Coleção Infância).

OLIVEIRA, Z. de M.R. de. Educação Infantil: fundamentos e métodos. São Paulo: Cortez, 2002.

Z. de M.R. de. O currículo na Educação Infantil: 0 que propõem as novas diretrizes nacionais? In: I Seminário Nacional: Currículo em Movimento - Perspectivas Atuais, p. 1-14. 2010. Belo Horizonte. Anais do I Seminário Nacional: Currículo em Movimento - Perspectivas Atuais. Belo Horizonte: UEMG, 2010. Disponível em: http://portal.mec. gov.br/docman/dezembro-2010-pdf/7153-2-1-curriculoeducacao-infantil-zilma-moraes/file (faltou incluir a data de acesso)

OSTETTO, L.E. (Org.) Educação Infantil: saberes e fazeres da formação de professores. Campinas, SP: Papirus, 2008.

PERRENOUD, P. Avaliação: da excelência à regulação das aprendizagens - entre duas lógicas. Tradução de Patricia Chittoni Ramos. Porto Alegre, RS: Artmed, 1996.

RINALDI, C. Pedagogy of listening: the listening perspective from Reggio Emilia. Innovation in early education: the international reggio exchange, vol.8, $n^{\circ} 04$. Wayne State University, Detroit, USA, p. 01-04, Fall, 2001.

RODRIGUES, P. As três "Iógicas" da avaliação de dispositivos educativos. In: ESTRELA, A.; RODRIGUES, P. Para uma fundamentação da avaliação em educação. Lisboa: Edições Colibri, 1994, p. 93-120.

SÃO PAULO. Portaria $n^{\circ}$ 4507/07, publicada no DOC de 31/08/2007. Institui, na Rede Municipal de Ensino, o Programa "Orientações Curriculares: Expectativas de Aprendizagens e Orientações Didáticas" para a Educação Infantil e Ensino Fundamental e dá outras providências. São Paulo: SME/DOT, 2007a.

Orientações Curriculares: Expectativas de Aprendizagens e Orientações Didáticas para Educação Infantil. São Paulo: SME/DOT-Ed. Infantil, 2007b. 
SARMENTO, M.J. Visibilidade social e estudo da infância. In: SARMENTO, M.J.; VASCONCELLOS, V.M.R. (Orgs.). Infância (in) visível. Araraquara, SP: Junqueira \& Marin Editores, 2007, p. 25-49.

SAUL, A.M. Avaliação Emancipatória: desafios à teoria e a prática de avaliação e reformulação de currículo. $4^{a}$ ed. São Paulo: Cortez, 1999.

SCRIVEN, M. The Methodology of Evaluation. In: TYLER, R.; GAGNE, R.; SCRIVEN, M. Perspectives of curriculum evaluation. Washington, D.C: American Educational Research Association, 1967.

THIOLLENT, M. Metodologia da pesquisa-ação. $13^{\mathrm{a}}$ ed., São Paulo: Cortez, 2004. 29

VYGOTSKY, L.S. (1930-5) Formação Social da Mente. $6^{a}$ ed., São Paulo: Martins Fontes, 1998.

WARSCHAUER, C. A roda e o registro: Uma parceria entre professor, alunos e conhecimento. São Paulo: Editora Paz e Terra, 1993.

WEFFORT, M.F. Observação, registro, reflexão. Instrumentos metodológicos I. São Paulo: Espaço Pedagógico, 1995.

ZABALZA, M.A. Diários de aula: um instrumento de pesquisa e desenvolvimento profissional. Tradução: Ermani Rosa. Porto Alegre, RS: Artmed, 1994.

Recebido em: 17/08/2016

Revisto em: 28/11/2016

Aceito em: 29/11/2016 